\title{
ÍNDICE DE AUTORES
}

Ana Paula de Castro SIERAKOWSKI 35

Ana Paula Pinheiro da SILVEIRA 35

$\begin{array}{ll}\text { Angel Humberto CORBERA MORI } & 91\end{array}$

$\begin{array}{lr}\text { Ariane TEIXEIRA } & 10\end{array}$

$\begin{array}{ll}\text { Bruna Gabriela Augusto Marçal VIEIRA } & 140\end{array}$

$\begin{array}{ll}\text { Camila de Araújo Beraldo LUDOVICE } & 207\end{array}$

$\begin{array}{ll}\text { Eliane Soares de LIMA } & 165\end{array}$

Elis de Almeida CARDOSO 72

Elisandra Aguirre da Cruz SCHWARZBOLD 50

$\begin{array}{ll}\text { Elisangela Maria da SILVA } & 127\end{array}$

Glória Maria Monteiro de CARVALHO 111, 127

$\begin{array}{ll}\text { Gustavo NISHIDA } & 35\end{array}$

$\begin{array}{lr}\text { Ivani Cristina Brito FERNANDES } & 50\end{array}$

$\begin{array}{ll}\text { Jacques FONTANILLE } & 246\end{array}$

$\begin{array}{ll}\text { Lucia TEIXEIRA } & 226\end{array}$

Luiza Monteiro de Barros OLIVEIRA 226

$\begin{array}{ll}\text { Marilurdes Cruz BORGES } & 207\end{array}$

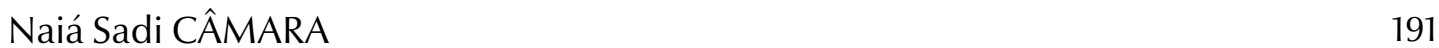

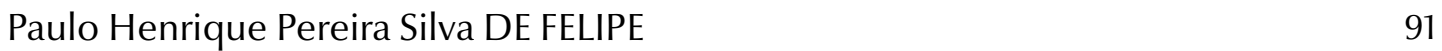

$\begin{array}{ll}\text { Renato Miguel BASSO } & 10\end{array}$

$\begin{array}{ll}\text { Sandra Mina TAKAKURA } & 72\end{array}$ 